\title{
HEMORRAGIA DIGESTIVA DE ORIGEN OSCURO SECUNDARIA A ANGIODISPLASIA DE INTESTINO DELGADO*
}

\author{
Dr. Nasser Eluzen G. ${ }^{1}$, Int. Cristóbal Nazar P. ${ }^{2}$, \\ Drs. Álvaro Tapia V. ${ }^{1}$, Guillermo Sepúlveda D. ${ }^{1}$ \\ 1 Servicio de Cirugía, Hospital Regional de Talca. \\ 2 Interno de Medicina, Pontificia Universidad Católica de Chile. \\ Chile.
}

\section{Obscure gastrointestinal bleeding secondary to small bowel angiodysplasia}

Paciente de sexo masculino de 35 años de edad, que consulta por melena de 90 días de evolución. La endoscopia digestiva alta y colonoscopia no evidenciaron sitio de sangrado.

Después de un episodio de lipotimia se realiza enteroclisis por TC que informa una malformación arterio-venosa probablemente en yeyuno proximal (Figura 1).

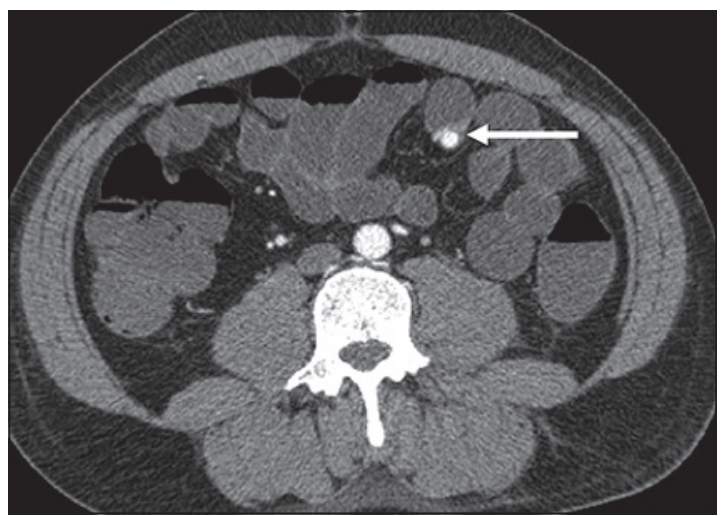

Figura 1. Enteroclisis por TC. Hallazgo de una malformación arterio-venosa en flanco izquierdo probablemente a nivel de yeyuno proximal (flecha).
Se realiza laparoscopia exploradora encontrando una zona solevantada, con características compatibles con una anomalía vascular ${ }^{1,2}$ (Figura 2). Se reseca la lesión junto a aproximadamente $6 \mathrm{~cm}$ de yeyuno (Figura 3). El paciente evolucionó satisfactoriamente y se da de alta al quinto día post operatorio, sin recurrencia del sangrado a los 3 meses de seguimiento.

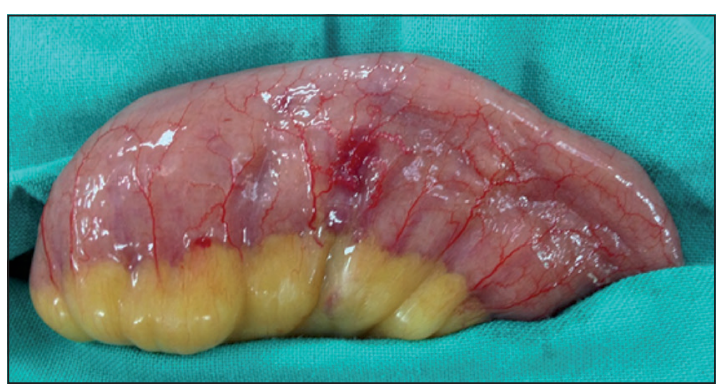

Figura 2. Pieza operatoria resecada a $210 \mathrm{~cm}$ del Treitz. Se observa una zona levemente solevantada, violácea, bien delimitada, con serosa conservada, compatible con una anomalía vascular de la pared intestinal del intestino delgado.

*Recibido el 10 de agosto de 2014 y aceptado para publicación el 22 de septiembre de 2014.

Los autores declaran no tener ningún tipo de conflicto de intereses.

Correspondencia: Cristóbal Nazar P.

canazar@uc.cl 


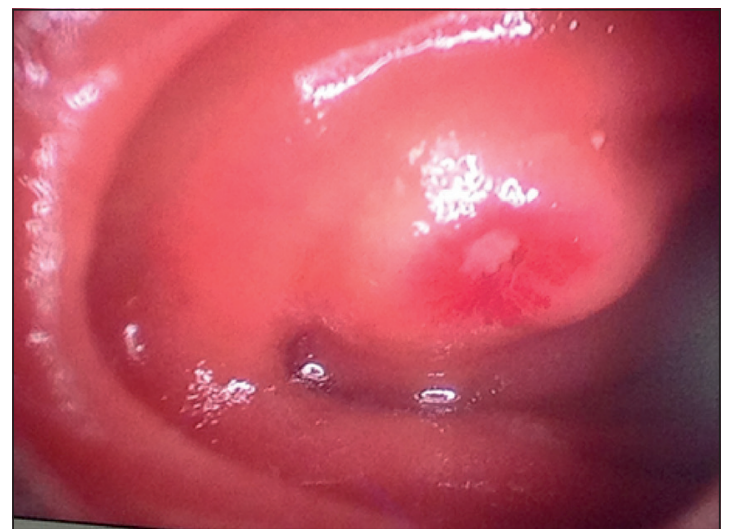

Figura 3. Imagen intraluminal de la pieza operatoria (yeyuno).

La biopsia de la pieza operatoria mostró hallazgos compatibles con angiodisplasia ${ }^{1,2}$ (Figura 4).

\section{Referencias}

1. Sami SS, Al-Araji SA, Ragunath K. Review article: gastrointestinal angiodysplasia-pathogenesis, diagnosis

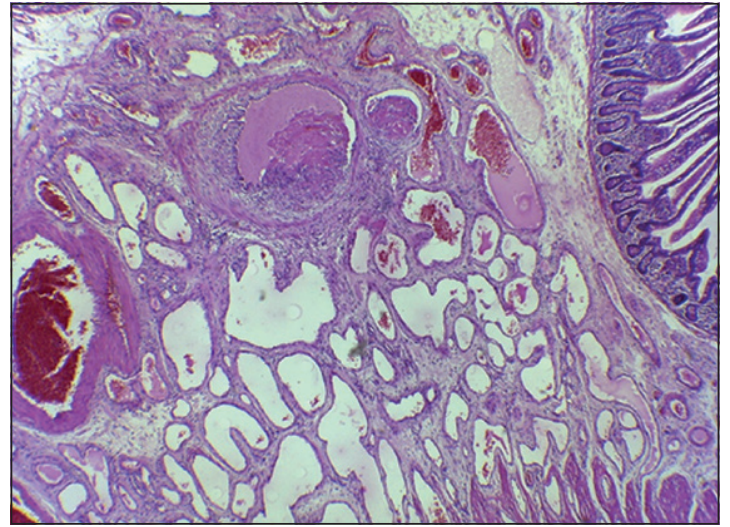

Figura 4. Biopsia de la pieza operatoria. Mucosa y submucosa de intestino delgado con numerosos vasos sanguíneos dilatados, con ausencia de capa muscular lisa, y sin atipías citológicas; hallazgos que demuestran una angiodisplasia de intestino delgado.

and management. Aliment Pharmacol Ther 2014;39:1534. Disponible en: http://www.ncbi.nlm.nih.gov/pubmed (Consultado el 10 de julio de 2014).

2. Jackson CS, Gerson LB. Management of Gastrointestinal Angiodysplastic Lesions (GIADs): A Systematic Review and Meta-Analysis Am J Gastroenterol. 2014;109:474-83. Disponible en: http://www.ncbi.nlm. nih.gov/pubmed (Consultado el 10 de julio de 2014). 